\title{
Experimental Investigation and Finite Element Analysis of the Free Vibration Problem of Bolted Joint by Taking Account of Interface Stiffness*
}

\author{
Toshimichi FUKUOKA**, Masataka NOMURA** and Nobukuni SUGANO** \\ ${ }^{* *}$ Faculty of Maritime Sciences, Kobe University \\ 5-1-1 Fukaeminami, Higashinada-ku, Kobe, Hyogo, 658-0022, Japan \\ E-mail: fukuoka@maritime.kobe-u.ac.jp
}

\begin{abstract}
Evaluation of the natural frequency and the natural mode of vibration of a bolted joint is particularly important to avoid the failure of the structure due to the resonance. The vibration characteristics of a bolted joint are largely influenced by such factors as the surface roughness of contact surfaces, the magnitude of axial bolt force, the arrangement of claming bolts, etc. In this paper, natural frequencies of the bending vibration of a bolted joint with simple configuration are measured with strain gages mounted on the surface of test specimen, and the effects of surface roughness, axial bolt force and bolt position are systematically investigated. Then, a numerical procedure is proposed to analyze the free vibration problem of a bolted joint, where the effect of interface stiffness due to surface roughness is incorporated into the finite element formulation. It is also presented that the computation efficiency for solving the eigen value problem can be fairly improved by introducing selective reduced integration (SRI) scheme. The effectiveness of the numerical procedure proposed here is validated by experimental measurements of the natural frequencies of the first mode.
\end{abstract}

Key words : Fixing Element, Bolted Joint, Natural Frequency, Free Vibration, FEM, Interface Stiffness, Selective Reduced Integration

\section{Introduction}

When designing machinery and structures, it is particularly important to evaluate natural frequencies of bolted joints in service condition with practical accuracy to avoid the failure due to resonance. A number of analytical methods have been proposed to calculate the natural frequencies ${ }^{(1)}$. Recently, finite element analysis has been applied extensively to analyze vibration problems of structures with complex geometry ${ }^{(2)}$. Machinery and structures are composed of many parts and they are clamped by a number of bolts and nuts. It is well known that natural frequencies of such bolted joints increase with larger clamping force. However, it is too premature to say that the numerical method, which can quantitatively evaluate the natural frequencies, has been established by taking the effects of surface roughness at the interface and axial bolt force into account. Meanwhile, contact pressure on the interface between plates exerts only within a limited area explained by pressure cone theory ${ }^{(3)}$, thus causing complicated vibration phenomena. Moreover, the distance between bolts also affects the vibration characteristics when tightening with multiple bolts. For the foregoing reasons, few studies have been devoted to the elucidation of the natural frequencies of bolted joints ${ }^{(4)}$. Most researches that dealt with vibration characteristics of bolted joints aim to detect joint imperfections ${ }^{(5),(6)}$, evaluate bolt force variations due to vibrating forces ${ }^{(7)}$, and suppress the resonance ${ }^{(8)}$.

In this paper, as a first step, bending vibration experiments are conducted using bolted joints with simple configuration to examine the effects of axial bolt force, surface roughness at the interface, bolt position on the magnitude of natural frequencies of bolted joints. Second, an equation relating axial bolt force to interface stiffness due to surface roughness is proposed 


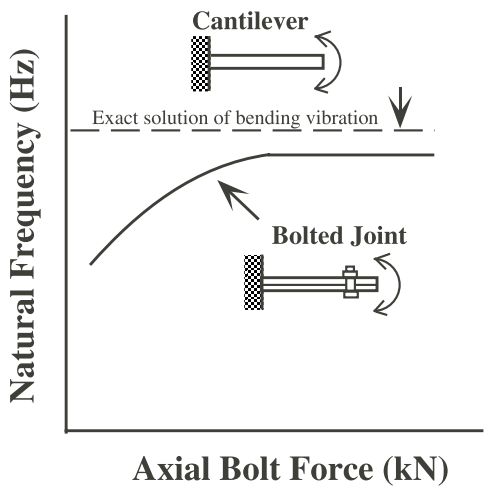

Fig. 1 Natural frequencies of bending vibration of bolted joint and cantilever

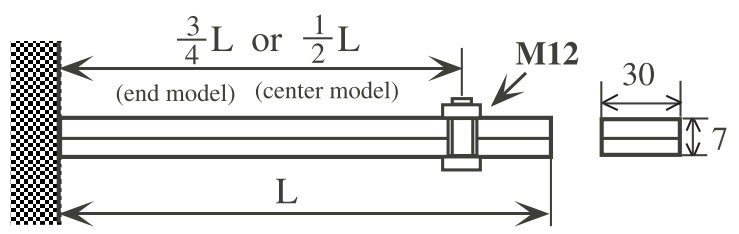

$\mathrm{L}=400,200,100$ (mm)

Fig. 2 Configuration of bolted joint models

in order to incorporate its relationship into finite element formulation of the vibration analysis. When analyzing vibration problems by FEM, selective reduced integration (SRI) scheme is introduced to analyze the free vibration problems of bending-dominant structures with sufficient accuracy using fewer elements. Thus, vibration characteristics of bolted joints are to be investigated systematically for various factors stated above. The validity of the proposed numerical method is demonstrated by comparing the natural frequencies of the first mode obtained by FEM with experimental results.

\section{Measurement of Natural Frequency of Bolted Joints}

\subsection{Natural frequency of bolted joint and bending vibration of cantilever}

Experimental investigation shows that natural frequencies of bolted joint consisting of two beams are lower and its damping ratios are larger than those of a single beam with same profile $^{(4)}$, termed equivalent single cantilever here. It is also pointed out that from the practical point of view, natural frequencies and natural modes of vibration can be evaluated by ignoring the damping effects ${ }^{(9)}$. In this section, natural frequencies of the first mode of bolted joint are measured by free bending vibration tests using bolted joints with simple geometry. Then, vibration characteristics of bolted joint are clarified by comparing the measured values to the exact solutions of the free vibration of equivalent single cantilever. Natural frequencies of a bolted joint consisting of two beams and equivalent single cantilever are schematically compared in Fig. 1. The natural frequency of the free vibration of cantilever is calculated by the following equation

$$
f=\frac{\lambda_{i}^{2}}{2 \pi L^{2}} \sqrt{\frac{E I}{\rho A}}
$$

$\lambda_{i} \mathrm{i}$ is eigen value of $i$ the ith mode of vibration. $L, I$ and $A$ represent length, second moment of area and area of the objective cantilever. $E$ and $\rho$ are Young's modulus [GPa] and density $\left[\mathrm{kg} / \mathrm{m}^{3}\right]$. It is presumed, as shown in Fig. 1, that the natural frequency of bolted joint increases with increasing axial bolt force and approaches a constant value beyond a certain bolt force. Even if clamping with sufficiently large bolt force, however, its natural frequency is to be 
Table 1 Specifications of test specimens

\begin{tabular}{|c|c|c|c|c|c|c|c|c|c|c|c|c|}
\hline $\begin{array}{l}\text { Beam length } \\
L(\mathrm{~mm})\end{array}$ & \multicolumn{4}{|c|}{$400 \mathrm{~mm}$} & \multicolumn{4}{|c|}{$200 \mathrm{~mm}$} & \multicolumn{4}{|c|}{$100 \mathrm{~mm}$} \\
\hline Bolt position & \multicolumn{2}{|c|}{$\frac{3}{4} L$} & \multicolumn{2}{|c|}{$\frac{1}{2} L$} & \multicolumn{2}{|c|}{$\frac{3}{4} L$} & \multicolumn{2}{|c|}{$\frac{1}{2} L$} & \multicolumn{2}{|c|}{$\frac{3}{4} L$} & \multicolumn{2}{|c|}{$\frac{1}{2} L$} \\
\hline $\begin{array}{c}\text { Surface } \\
\text { roughness }\end{array}$ & fine & rough & fine & rough & fine & rough & fine & rough & fine & rough & fine & rough \\
\hline$R_{\mathrm{mt}}(\mu \mathrm{m})$ & 2.6 & 18.8 & 3.0 & 22.0 & 3.4 & 28.2 & 3.7 & 29.3 & 4.6 & 30.2 & 6.0 & 33.0 \\
\hline $\begin{array}{l}\text { Symbol of } \\
\text { specimen }\end{array}$ & \multicolumn{2}{|c|}{ 400A-f } & \multicolumn{2}{|c|}{ 400B-f } & \multicolumn{2}{|c|}{ 200A-f } & \multicolumn{2}{|c|}{ 200B-f } & \multicolumn{2}{|c|}{ 100A-f } & \multicolumn{2}{|c|}{$\begin{array}{l}\text { 100B-f } \\
\text { 100B-r }\end{array}$} \\
\hline
\end{tabular}

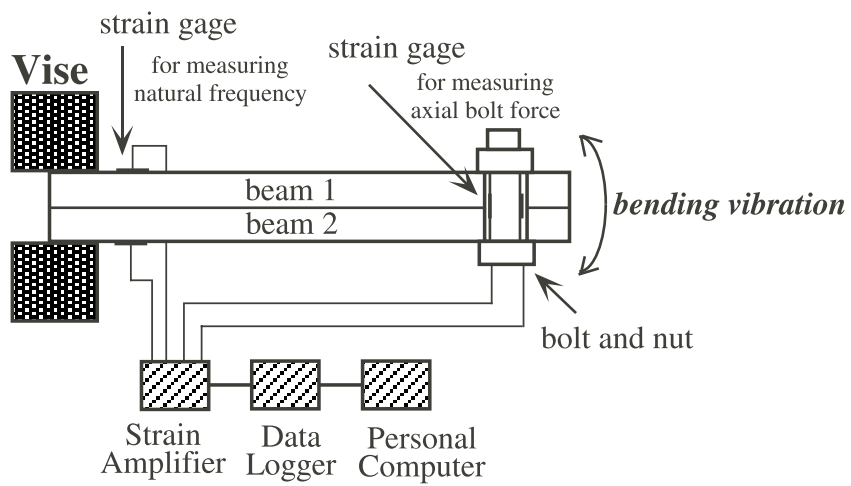

Fig. 3 Experimental setup for measuring natural frequencies of bolted joints

lower than that of equivalent single cantilever. That is because the interface stiffness due to surface roughness lowers the total joint stiffness and only the limited area of plate interface is subjected to contact pressure.

\subsection{Test specimens of bolted joints}

A test specimen is a bolted joint composed of two identical beams clamped with a single M12 bolt, as shown in Fig. 2. The width and height of the beams are $30 \mathrm{~mm}$ and $3.5 \mathrm{~mm}$, thus the total height of bolted joint is $7 \mathrm{~mm}$. Beam length is changed as $400 \mathrm{~mm}, 200 \mathrm{~mm}$ and $100 \mathrm{~mm}$. The clamping bolt is placed either at the end or the center of test specimen for each case. These models are designated as end model and center model, respectively. Surface roughness is varied into two levels for each specimen, i.e., fine and rough, to examine its effects on the natural frequencies. Thus, six specimens with different configurations are prepared and free vibration experiments are conducted under twelve boundary conditions, as tabulated in Table 1. A vertical milling machine and a surface grinder were used for the surface finish of test specimens. These specimens are distinguished by the figures representing its length, prefixes of "A" and " $\mathrm{B}$ " indicating bolt positions of end and center, and " $\mathrm{f}$ " and " $\mathrm{r}$ " expressing fine and rough surface conditions. As far as surface roughness is concerned, $R_{\mathrm{mt}}$, which is the sum of maximum height roughness $R_{\max }$ of mating surfaces, is adopted here to quantitatively evaluate the interface stiffness. Measured values of $R_{\mathrm{mt}}$ are shown in Table 1, in which $R_{\mathrm{mt}}$ varies from 2.6 to $6.0 \mu \mathrm{m}$ for fine surfaces and from 18.8 to $33.0 \mu \mathrm{m}$ for rough surfaces.

\subsection{Experimental Setup}

Figure 3 schematically shows the experimental setup. One end of the specimen is fixed by means of a vise, and at the other end small force is applied in the vertical direction to cause free bending vibration. Natural frequencies are measured by a strain gage mounted near the fixed end. Bending vibration of the cantilever periodically changes the sign of measured strains between tension and compression, thus the natural frequency of the first mode is calculated from the oscillating period. Bolt tightening operation is carried out using a spanner. Axial bolt force $F_{b}$ is changed such as $0,1,2,3,5,10,15,20(\mathrm{kN})$, monitoring the output of two 


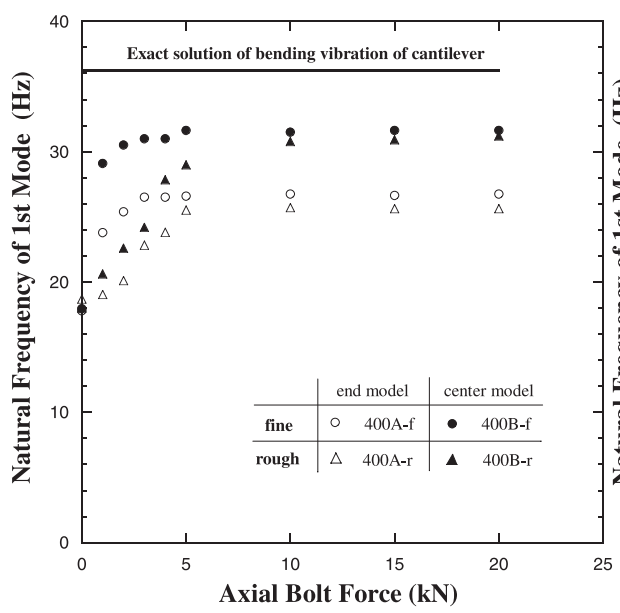

(a) $\mathrm{L}=400 \mathrm{~mm}$

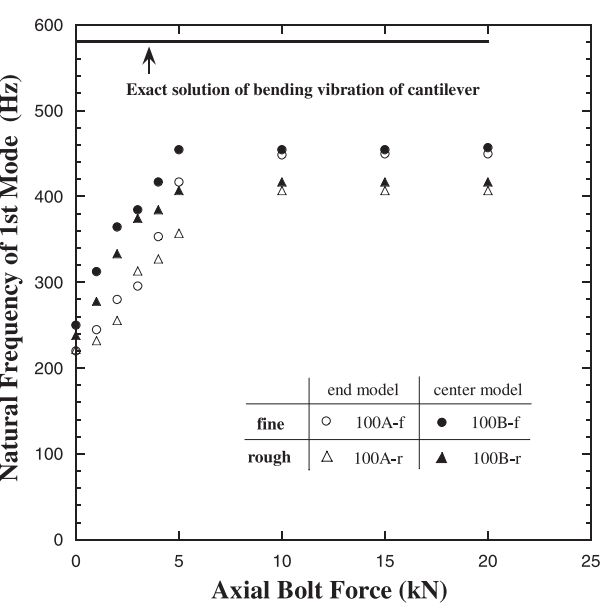

(b) $\mathrm{L}=100 \mathrm{~mm}$

Fig. 4 Experimental results of natural frequencies of bolted joint

Table 2 Ratio of the first order natural frequencies of bolted joint to cantilever

\begin{tabular}{|c|c|c|c|c|c|c|c|c|c|c|c|c|}
\hline $\begin{array}{l}\text { Beam length } \\
L(\mathrm{~mm})\end{array}$ & \multicolumn{4}{|c|}{$400 \mathrm{~mm}$} & \multicolumn{4}{|c|}{$200 \mathrm{~mm}$} & \multicolumn{4}{|c|}{$100 \mathrm{~mm}$} \\
\hline Bolt position & & $L$ & & $L$ & & $L$ & & $L$ & & $L$ & & $L$ \\
\hline $\begin{array}{l}\text { Surface } \\
\text { condition }\end{array}$ & fine & rough & fine & rough & fine & rough & fine & rough & fine & rough & fine & rough \\
\hline$\frac{f_{\text {bolted joint }}}{f_{\text {cantilever }}}$ & 0.739 & 0.709 & 0.874 & 0.862 & 0.765 & 0.725 & 0.861 & 0.810 & 0.774 & 0.700 & 0.787 & 0.718 \\
\hline
\end{tabular}

strain gages mounted on the bolt body. The condition of $F_{b}=0$ corresponds to "finger tight". To examine the effectiveness of the measuring method by use of strain gages, a high-speed digital camera was used to directly measure the natural frequencies from vibrating images of the test specimen. It can digitize up to 2000 images per second with resolution of 512 times 144 pixels and store 2048 images in all. The natural frequencies measured by the camera images agreed extremely well with those by strain gages.

\subsection{Experimental Results}

Figure 4(a) shows the effects of axial bolt force $F_{b}$ on the first mode natural frequencies of the specimens with $400 \mathrm{~mm}$ length. Also shown in the figure is the natural frequency of equivalent single cantilever. Natural frequencies of the bolted joints are entirely lower than that of equivalent single cantilever due to the effect of interface stiffness. Center model produces higher natural frequencies than does end model. It is worth noting that measured natural frequencies approximately become the half of equivalent single cantilever case as $F_{b}$ approaches zero. That is because the natural frequency of cantilever is simply proportional to the beam height as found from Eq. (1). It is considered, therefore, that in the case of finger tight, deformations of the two beams are constrained very slightly between bolt and nut, thus producing the natural frequency of cantilever with $3.5 \mathrm{~mm}$ height. Figures 4 (b) shows the results of $100 \mathrm{~mm}$ specimen. Although natural frequencies in the figure are higher than those in Fig. 4(a) because of short beam length, they also approach certain constant values with increasing axial bolt force. When $F_{b}=0$, natural frequencies of the bolted joints are slightly lower than the half of equivalent single cantilever case, the reason being that the effect of mass of bolt and nut reveals for shorter beam length. The ratios of the first mode natural frequencies of bolted joints, which are clamped with sufficient high bolt forces, to those of equivalent single cantilever are tabulated in Table 2. The experimental results are summarized as follows.

(1) End model produces lower natural frequencies than center model, which is rather remarkably observed with larger beam length.

( 2 ) Natural frequencies of bolted joint approach constant values beyond some amount 


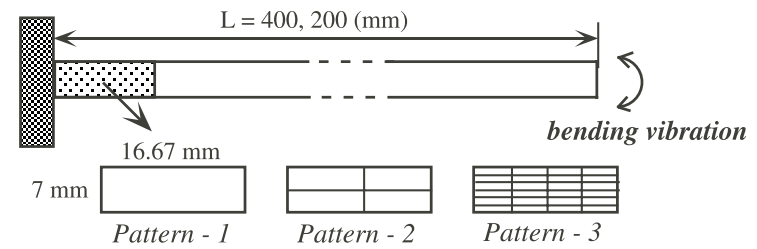

Fig. 5 Numerical models for bending vibration problems with SRI

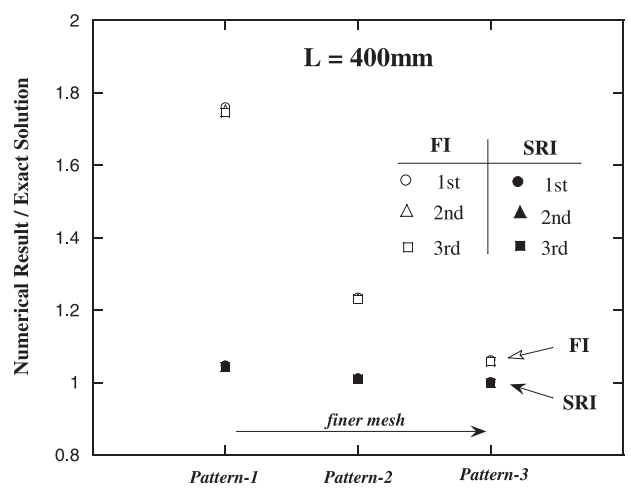

Fig. 6 Numerical results of natural frequencies with SRI

of axial bolt force. For specimens with finer surface, this phenomenon occurs at lower bolt force.

( 3 ) Smaller surface roughness generates higher natural frequencies, whose effect is somewhat explicitly recognized in the case of shorter beams. No significant difference is observed between center model and end model.

\section{Analysis of Free Vibration Problem of Bolted Joints by Taking Account of} Interface Stiffness

\subsection{Analysis of bending vibration of cantilever with selective reduced integration}

When analyzing natural frequencies and modes of vibration by FEM, it requires more computing time than does the stress analysis of the structure with same configuration. Nonconforming elements are sometimes used to achieve high accuracy with fewer elements ${ }^{(10),(11)}$. In this study, selective reduced integration (SRI) scheme ${ }^{(12)}$ is applied to free vibration problems and its effectiveness is examined. It has been successfully applied in the previous paper when modeling a crank pin bolt of diesel engine as a rectangular thick plate composed of four-node bilinear elements ${ }^{(13)}$. When carrying out the integration of element stiffness matrix, full integration (FI) and reduced integration (RI) are applied to the components that relate to normal and shear stresses, respectively. Figure 5 illustrates the numerical models adopted here. Corresponding to the foregoing experimental conditions, three beams, $400 \mathrm{~mm}, 200 \mathrm{~mm}$ and $100 \mathrm{~mm}$ lengths with $7 \mathrm{~mm}$ height, are modeled. Mesh division patterns are varied in three ways as shown in Fig. 5. Natural frequencies and modes of vibration are solved by FEM as generalized eigen value problem ${ }^{(2)}$.

$$
[K]\{u\}=\lambda[M]\{u\}
$$

$[K], \lambda$ and $\{u\}$ denote global stiffness matrix, eigen value and eigen vector. Mass matrix $[M]$ is formulated in accordance with lumped mass matrix theory. Four-node bilinear elements are used in all FE analyses. Eigen value problems are solved by Generalized Jacobi Method. Figure 6 shows the numerical results of natural frequencies of cantilever from the first to third modes. The ordinate represents the ratio of numerical results to theoretical values calculated by Eq. (1). Young's modulus $E$ and density $\rho$ are set to be $200[\mathrm{GPa}]$ and $7800\left[\mathrm{~kg} / \mathrm{m}^{3}\right]$. When applying FI scheme, numerical values gradually approach the theoretical ones as the 
mesh size is decreased. On the other hand, SRI scheme has achieved high accuracy with coarser meshes. For shorter beams with $200 \mathrm{~mm}$ and $100 \mathrm{~mm}$ lengths, though FI gives slightly higher accuracy, similar results are obtained. Accordingly, SRI scheme is applied to all of the numerical analyses in the later sections.

\subsection{Evaluation of interface stiffness ${ }^{(14)}$}

The increase of natural frequencies of bolted joints, when axial bolt force is increased, is primarily due to the crush of asperities at the interface, which produces higher joint stiffness. Approach of interface $\delta[\mu \mathrm{m}]$ due to the deformations of surface asperities and contact pressure $p_{n}[\mathrm{MPa}]$ can be related by the following equation proposed by Ostrovskii( ${ }^{(15)}$.

$$
\delta=c p_{n}{ }^{m}
$$

where $c$ and $m$ are constants. These constants can be expressed as a function of $R_{\mathrm{mt}}$, the sum of maximum height roughness $R_{\max }$ of the mating surfaces, employing the experimental data by Taniguchi et al. ${ }^{(16),(17)}$.

$$
\begin{aligned}
c & =0.0674 R_{\mathrm{mt}}+0.413 \\
m & =0.0155 R_{\mathrm{mt}}+0.155
\end{aligned}
$$

The maximum value of $m$ is set to be 0.5 referring to Ref. (18). Using Eq. (3), the spring rate in the normal direction due to interface stiffness, $k_{n}$, is derived as follows.

$$
k_{n}=\frac{\mathrm{d} F_{n}}{\mathrm{~d} \delta}=\frac{A}{m c} p_{n}{ }^{1-m}
$$

$F_{n}$ is the normal force exerting on the contact surface and $A$ denotes the contact area. Meanwhile, the spring rate in the tangential direction, $k_{t}$, can be related to $k_{n}$ using the equations proposed by Kirsanova and Back. Kirsanova suggests that the surface deformation in the tangential direction, $\zeta$, can be expressed as the product of shear stress $p_{t}$ and shear compliance $K_{t}$ in the tangential direction ${ }^{(19)}$.

$$
\zeta=K_{t} p_{t}
$$

Back proposes an equation that relates $K_{t}$ to $p_{n}$ in terms of constants $R$ and $S$ given for each material $^{(18)}$.

$$
K_{t}=\frac{R}{p_{n}{ }^{s}}
$$

Accordingly, the equation for calculating $k_{t}$ is derived as the product of the first derivative of $p_{t}$ with respect to $\zeta$ and contact area $A$. Using Eqs. (6) and (7), the expression for $k_{t}$ is derived, and then it is related to $k_{n}$, assuming that $\zeta$ is independent of $p_{n}$.

$$
k_{t}=\frac{c m}{R} p_{n}{ }^{m+S-1} \times k_{n}
$$

Equation (8) shows that the magnitude of $k_{t}$ can be calculated in terms of $k_{n}, p_{n}$ and four constants $c, m, R, S$. According to Back's research ${ }^{(18)}, S$ is 0.5 and $R$ is calculated by the following equation.

$$
\frac{R}{c m}=2(1+v)
$$

where $v$ is Poisson's ratio. It is evident from the foregoing equations that the spring rates, $k_{n}$ and $k_{t}$, can be obtained when surface roughness $R_{\mathrm{mt}}$, contact pressure $p_{n}$ and contact area $A$ are known. 


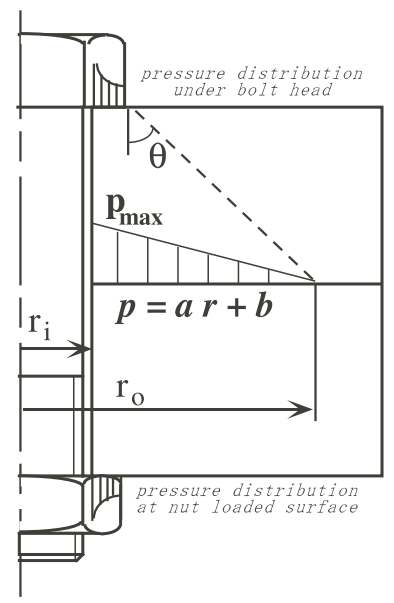

Fig. 7 Contact pressure distributions at the interface of plates due to axial bolt force

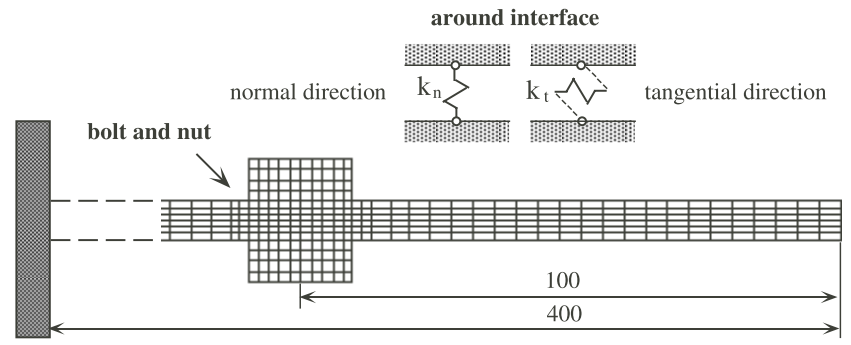

Fig. 8 Finite element model of bolted joint $(L=400 \mathrm{~mm})$

\subsection{Numerical models}

Figure 7 shows a bolted joint composed of two plates clamped by a single bolt. Four contact surfaces exist such as pressure flank of threads, nut loaded surface, bolt head loaded surface and plate interface. Each surface is subjected to contact pressure produced by axial bolt force $F_{b} . F_{b}$ exerts very high contact pressure on the first pressure flank of engaged threads. Contact pressures on the nut loaded surface and bolt head loaded surface are also fairly high, i.e., 60 to 80 percent of the axial bolt stress, considering the area ratio of bolt cross section to nut loaded surface. According to pressure cone theory, pressure distribution pattern at the plate interface is usually divided into three categories, such as thin plate, thick cylinder and thin cylinder. From the joint geometry, the present analytical object is thin plate ${ }^{(3)}$, which means that the plate interface away from bolt axis is slightly in contact without contact pressure. Assuming that the contact pressure $p$ varies linearly in the radial direction, the maximum pressure $p_{\max }$ occurs along the bolt hole, and $p$ at radial position of $r$ is calculated for given bolt force $F_{b}$ as follows ${ }^{(14)}$. The angle of frustum cone $\theta$ exerting contact pressure on the plate interface is assumed to be 45 degrees.

$$
\begin{aligned}
p_{\max } & =\frac{3 F_{b}}{\pi\left(r_{o}^{2}+r_{o} r_{i}-2 r_{i}^{2}\right)} \\
p_{n} & =-\frac{p_{\max }}{r_{o}-r_{i}}\left(r-r_{o}\right)
\end{aligned}
$$

$r_{i}$ and $r_{o}$ are radii of bolt hole and the outer end under contact pressure. In the FE analyses in the next chapter, the magnitude of contact pressure $p_{n}$ at each node is calculated using Eq. (10). Contact area $A$ in Eq. (5) is equated to the corresponding area of each contacting node. Using $p_{n}$, the spring rates, $k_{n}$ and $k_{t}$, which represent the interface stiffness in the normal and tangential directions, are calculated following the procedure explained in sec 3.2. Threedimensional analysis is required for actual bolted joints, since the pressure cone spreads in all directions from bolt axis. Considering the primary purpose the present study, however, the use 


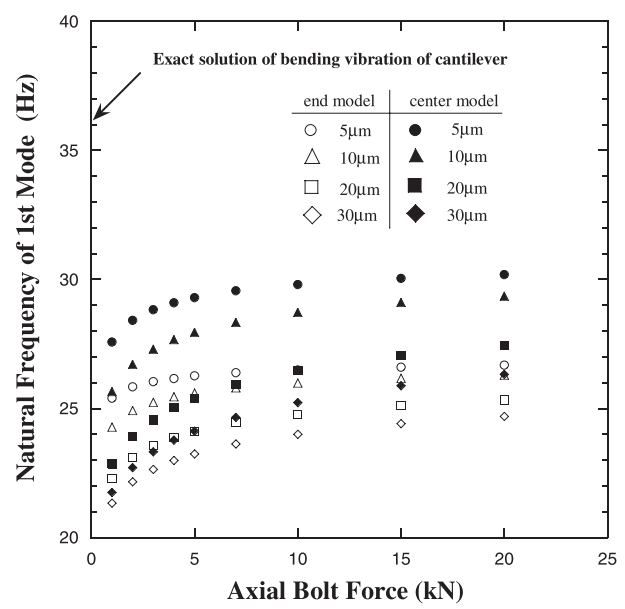

Fig. 9 Numerical results of natural frequencies of bolted joint

of two-dimensional models is practically sufficient. Natural frequencies and natural modes of vibration are calculated, assuming that;

(1) Only the interface stiffness between plates, which has the primary effect on the vibration characteristics, is taken into account.

( 2 ) The magnitude of contact pressure on the plate interface, where the bolt model being overlapped, is supposed to be half the maximum pressure $p_{\max }$.

Six numerical models are prepared corresponding to the test specimens listed in Table 1. Figure 8 illustrates the mesh pattern around bolt and nut. A pair of nodes, placed on the mating surfaces of two beams, is connected by two springs, whose spring rates are $k_{n}$ and $k_{t}$, in the normal and radial directions. The mesh size is selected so as to provide sufficient accuracy, referring to Fig. 6. To make the numerical calculation easy, threads and bolt hole are not modeled, and bolt and nut are treated as a part of upper or lower beam. Surface roughness $R_{m t}$ is changed as 5,10,20,30,50 $\mu \mathrm{m}$. Since two-dimensional models are used, the density of bolt head and nut is modified to be consistent with the mass of the actual bolted joint.

\section{Numerical Results}

\subsection{Effects of axial bolt force and surface roughness}

Figure 9 shows the numerical results for the cantilever with $400 \mathrm{~mm}$ length. For comparison, the exact solution of equivalent single cantilever with $7 \mathrm{~mm}$ height is also shown. In any case, natural frequencies increase with increase of $F_{b}$ and almost become constant beyond a certain value of $F_{b}$. Saturated values of the natural frequency are entirely lower than those of equivalent single cantilever. When $F_{b}$ approaches zero, natural frequencies of the bolted joint approach that of the cantilever with $3.5 \mathrm{~mm}$ height $(18.1 \mathrm{~Hz})$, as in the case of the experimental results shown in Fig. 4. As for surface roughness $R_{\mathrm{mt}}$, natural frequencies decrease as $R_{\mathrm{mt}}$ is increased. It is also shown that center model produces higher natural frequencies than does end model. It follows, therefore, that the numerical results of natural frequencies show similar tendencies to experimental ones concerning the effects of axial bolt force $F_{b}$, surface roughness $R_{\mathrm{mt}}$ and bolt position.

\subsection{Comparison with experimental results}

Figure 10(a) compares the numerical and experimental results of end model and center model with $400 \mathrm{~mm}$ length, where the surface roughness of numerical analysis $R_{\mathrm{mt}}$ is set to be $10 \mu \mathrm{m}$ and $30 \mu \mathrm{m}$. Experimental results given in Fig. 4(a) are also shown in the figure. Figure 10(b) represents the results for the case of $L=200 \mathrm{~mm}$. The differences between numerical and experimental results are somewhat larger in shorter beam and center model. It is found, however, that numerical results by FEM fairly well evaluate the effects of axial bolt 


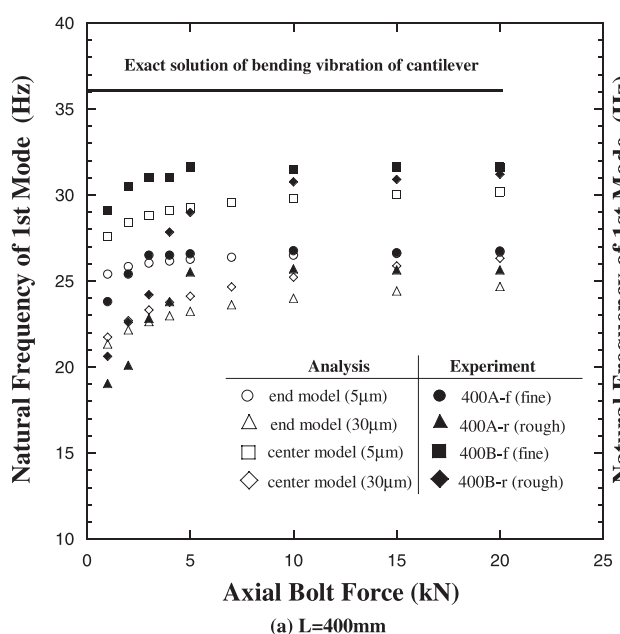

(a) $\mathrm{L}=400 \mathrm{~mm}$

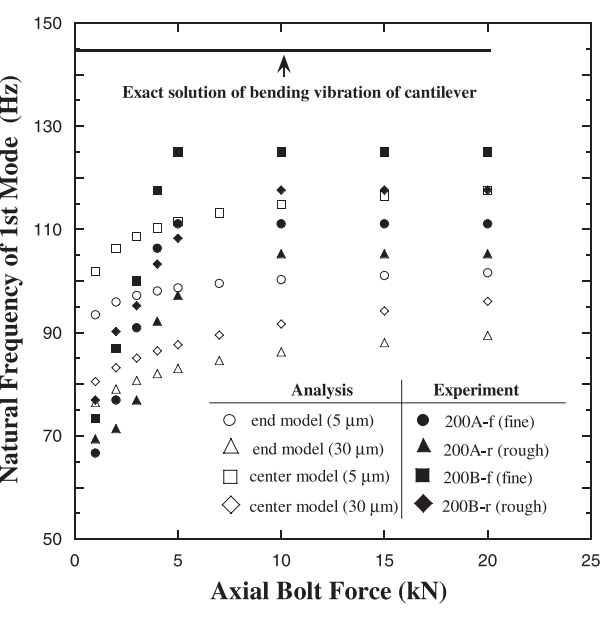

(b) $\mathrm{L}=\mathbf{2 0 0 \mathrm { mm }}$

Fig. 10 Comparison of numerical and experimental results

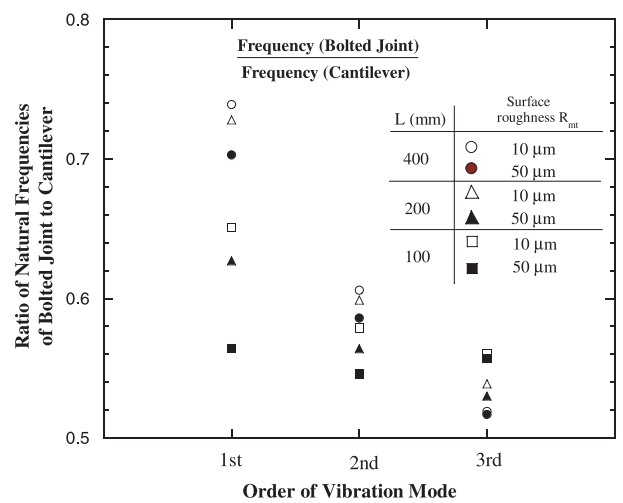

Fig. 11 Ratio of natural frequencies of bolted joint to cantilever

force, surface roughness and bolt position on the magnitude of natural frequencies of bolted joints. The difference in the numerical accuracy for varying beam length, which is rather remarkable in shorter beams, is caused by employing two-dimensional models. It is therefore concluded that the numerical method proposed in this study is effective, from the practical point of view, to analyze natural frequencies of bolted joints by taking account of the effect of interface stiffness.

\subsection{Discussions}

Higher modes of vibration of bolted joints are discussed. Natural frequencies and modes of vibration up to the fifth mode are analyzed here. It was found that the free vibration modes of cantilever appeared in the complex manner ranging from the first to third modes, especially in center model for varying axial bolt force, surface roughness and bolt position. Accordingly, numerical results of end model are shown here. First and second modes of the bolted joints are entirely analogous to those of bending vibration of equivalent single cantilever. The third mode of bolted joint is similar to that of the second mode of cantilever, and the fourth mode appears rather similarly to the third mode of cantilever when axial bolt force is high. In addition, the third mode of cantilever is found in some cases of the fifth mode of bolted joint.

Figure 11 shows the ratio of natural frequencies of end model clamped with axial bolt force of $20 \mathrm{kN}$ to equivalent single cantilever. The ordinate represents the ratio of the two natural frequencies, and the abscissa is the order of vibration. Shown in the figure are the natural frequencies of bolted joint whose natural modes are analogous to those of cantilever with $7 \mathrm{~mm}$ height. Natural frequencies of the bolted joints tend to be smaller comparing to 
those of equivalent single cantilever with increase of the order of vibration. This phenomenon agrees with the experimental results given in Ref. (4). It is also observed that the ratios of the natural frequencies are fairly affected by the surface roughness $R_{\mathrm{mt}}$ at the plate interface.

\section{Conclusions}

( 1 ) A numerical approach based on FEM is proposed to evaluate natural frequencies and natural modes of vibration of bolted joints by taking the effect of interface stiffness due to surface roughness into account.

(2) The effects of surface roughness, axial bolt force and bolt position on the natural frequencies of bolted joint are quantitatively examined by simple bending vibration experiments.

( 3 ) Natural frequency of bolted joint is lower than that of one-body structure with same configuration, and it increases with larger bolt force and becomes constant beyond a certain bolt force. It also increases with smaller surface roughness and approaches a constant value at lower axial bolt force.

( 4 ) Selective reduced integration (SRI) scheme can successfully be incorporated into finite element formulation to analyze bending-dominant vibration problems with high computation efficiency with fewer elements.

( 5 ) The validity of the numerical approach proposed here is demonstrated by measuring the natural frequencies of the first mode of bolted joints with simple geometry.

The authors would like to acknowledge Prof. Emeritus Kouhei Suzuki, Tokyo Metropolitan University, for his support on the numerical analysis of vibration problems, and Mr. Satoshi Nakano and Mr. Toshiharu Suzuki for their works on vibration experiments.

\section{References}

(1) The Japan Society of Mechanical Engineers ed., Fundamentals and Applications of Mode Analysis, (1986), Maruzen.

( 2 ) Bathe, K. J. and Wilson, E. L. (translated by Kikuchi, F.), Numerical Methods in Finite Element Analysis, (1980), pp.470-576, Kagaku-Gijyutsu Publishing

( 3 ) Yamamoto, A., Theory and Practice of Tightening Process of Screw Threads, (1970), pp.49-52, Yokendo.

( 4 ) Aoki, S., Dynamic Characteristics of Structures with Bolted Joint, Analysis of Bolted Joints, PVP-Vol.433, (2002), pp.75-79.

( 5 ) Esteban, J. and Rogers, C. A., Energy Dissipation through Joints: Theory and Experiments, Computers and Structures, Vol.75, (2002), pp.347-359.

( 6 ) Sodano, H. A., Park, G and Inman, D., An Investigation into the Performance of Microfiber Composites for Sensing and Structural Vibration Applications, Mechanical Systems and Signal Processing, Vol.18, (2004), pp.683-697.

( 7 ) Basava, S. and Hess, D. P., Bolted Joint Clamping Force Vibration due to Axial Vibration, Journal of Sound and Vibration, Vol.210-2, (1998), pp.255-265.

( 8 ) Gaul, L. and Nitsche, R., Friction Control for Vibration Suppression, Mechanical Systems and Signal Processing, Vol.14, (2000), pp.139-150.

( 9 ) JSME, Dynamics of Mechanical Systems, (1991), pp.63-93, Ohmsha.

(10) Kawai, T. and Kishi, M., Introduction to FEM for Machinery, (1983), pp.213-235, Ohmsha.

(11) Washizu, K., Miyamoto, H., Yamada, Y., Yamamoto, Y. and Kawai, T., FEM Handbook (Volume I), Baifukan, (1981), pp.263-270.

(12) Fukuoka, T. and Senoh, Y., Finite Element Simulation of the Strength of the Big End of Diagonally Split Connecting Rod, Transactions of the Japan Society of Mechanical Engineers, Series A, Vol.64, No.617 (1998), pp.104-110.

(13) Kikuchi, N., Finite Element Methods in Mechanics, (1986), pp.218-220, Cambridge University Press.

(14) Fukuoka, T., Analysis of the Tightening Process of a Bolted Joint with a Tensioner 
-Effects of Contact Stiffness-, Transactions of the Japan Society of Mechanical Engineers, Series A, Vol.61, No.582 (1995), pp.429-435.

(15) Ostrovskii, V.I., The Influence of Machining Methods on Sideway Contact Stiffness, Machines and Tooling, Vol.36, No.1 (1965), pp.17-19.

(16) Taniguchi A, Tsutsumi M and Ito Y., Treatment of Contact Stiffness in Structural Analysis - 1st Report, Mathematical Model of Contact Stiffness and Its Applications, Bulletin of JSME, Vol.27, No.225 (1984), pp.601-607.

(17) Fukuoka, T., Evaluation of the Tightening Process of Elastic Angle Control Method and Proposal of a Practical Tightening Operation, Transactions of the Japan Society of Mechanical Engineers, Series C, Vol.72, No.716 (2006), pp.1370-1377.

(18) Back, N., Burdekin, M. and Cowley, A., Analysis of Machine Tool Joints by the Finite Element Method, 14 ${ }^{\text {th }}$ Int. MTDR Conference, Paper No.210, (1973), pp.529-539.

(19) Kirsanova, V.N., The Shear Compliance of Flat Joints, Machine and Tooling, Vol.38, No.7 (1967), pp.30-34. 